\title{
Understanding and Managing Complete form of Sporadic Koro Syndrome associated with Depression
}

\author{
Mahima Panigrahi, Susanta Kumar Padhy, Prakash B Behere
}

\begin{abstract}
Koro is a term, probably of Malayasian origin, a culture bound syndrome, which refers to an episode of sudden and intense anxiety that the penis will recede into the body and possibly cause death. The syndrome is reported in South and East Asia including Eastern India, occasionally found in west. It can occur in localized epidemic and sporadic form or in complete and incomplete form. In some, this is reported as a forerunner of mood disorder and is understood in the context of psychosexual conflicts, personality and culture. Moreover, reports of sporadic Koro are rare from Noneastern India and report of a holistic and comprehensive approach to understand and manage such cases are lacking. Hence, In today's era of extinction of psychotherapeutic treatments particularly in India, this rare case is a small example of how such comprehensive holistic treatments can be helpful to our population.
\end{abstract}

Keywords: Koro syndrome, Sporadic koro, Management, Conceptualization.

How to cite this article: Panigrahi M, Padhy SK, Behere PB. Understanding and Managing Complete form of Sporadic Koro Syndrome associated with Depression. J Postgrad Med Edu Res 2012;46(2):104-105.

\section{Source of support: Nil}

Conflict of interest: None declared

\section{INTRODUCTION}

Koro is a term, probably of Malayasian origin, a culture bound syndrome, which refers to an episode of sudden and intense anxiety that the penis will recede into the body and possibly cause death ${ }^{1,2}$ The syndrome is reported in South and East Asia (including Eastern India), ${ }^{3}$ where it is known by variety of local terms, such as shuk yang, shook yong, and suo yang (Chinese); Jin jinia bemar (Assam); or rokjoo (Thailand); ${ }^{1,3}$ occasionally found in west. ${ }^{4}$ It occurs in localized epidemic and sporadic form; in complete and incomplete form. ${ }^{3,5}$ In two sporadic cases, Koro has been reported as a forerunner of mood disorder. ${ }^{6}$ Koro has been understood in the pretext of psychosexual conflicts, ${ }^{7}$ personality dimensions ${ }^{8}$ and in cultural context in some. Reports of sporadic Koro are rare from Noneastern India region $^{9}$ and a holistic approach to understand and manage such cases is lacking. Hence, we describe and discuss a case of complete sporadic Koro followed by depressive disorder from central India.

Mr G is a 37-year-old under-matric married man from middle socioeconomic status of rural background, hailing from Orthodox Hindu joint family of Central India. He was brought up by authoritative, strict, over disciplined, moralistic and controlling father supported by docile and submissive mother. Personality wise Mr $\mathrm{G}$ is immature, nonassertive, dependent, indecisive, passive, anxious and insecure. He had no source of income or shelter. Before marriage, he had guilt over masturbation (in spite, masturbate excessively); nocturnal emission; and had two instances of a promiscuous physical relationship, where he felt sexually inadequate. He refrained away from it, subsequently, because he felt sexually incompetent, in spite of desire. However, no erectile dysfunction or premature ejaculation, he reported. After marriage (3 years back), spouse exerted her dominant, authoritative, over demanding attitude over patient and in-laws resulting in unsatisfactory sexual life and impaired interpersonal relationship among the infertile couple and in-laws. Often, wife passed critical comments in relation to poor sexual performance that would hurt Mr G. Other past or family history were nil significant.

Ten months back, following a physical fight with father over property dispute, father abandoned Mr G and wife left to her parental home. Next day, he complained that his penis had shortened and was retracting into abdomen, associated with severe anxiety and fear that this would ultimately cause death. These were occurring in episodes of 5 to 15 hours, daily. Mr G would pull penis by putting hand inside the trouser-pocket as an attempt to prevent penile retraction but with vain. A month later, started remaining sad, worried increasingly about penile retraction, fear of performance, sleeplessness, deceased appetite, remained aloof, lost interest, anhedonia, weeping, helpless and hopeless. In due course, attempted suicide and admitted to psychiatry ward. On examination, pressure mark on the shaft of penis, sad and anxious look, and depressive cognitions with observable behavior of pulling out the penis in ward was noted. Psychometry revealed sexual conflicts, preoccupation with sex, insecurity, high trait anxiety and depression. Sexual knowledge was poor on SKAQ (sexual knowledge and attitude questionnaire).$^{10}$ Routine investigations were normal. He was started on duloxetine $20 \mathrm{mg} /$ day and low dose clonazepam. After 4 weeks, depressive symptoms improved moderately and slight improvement in "Koro symptoms". Sessions were taken with patient, wife and father to resolve the social issues (including property dispute) with the help of social worker. Psychoeducation and psychotherapy sessions were taken focusing on Koro, 
poor sexual knowledge and relationship issues. Employment opportunities were discussed with patient and family. Biofeedback sessions and relaxation techniques taught. Koro symptoms improved significantly and patient is maintaining well till a couple of months ago.

\section{DISCUSSION}

Mr G seemingly had sexual conflicts (desire to masturbate excessively and feeling guilt over it; wished physical relation and remained away from it because of feeling of sexual inadequacy; infertile couple); had conflict with 'significant parental figure', father (did not like father and at the same time completely dependent on father); chronic psychosocial stressors (no source of income, no shelter, relationship problems). There are reports of Koro in individuals with such conflicts. ${ }^{3,4,6,7}$ To conceptualize the index case, an insecure, inefficient anxious sterile individual with psychosexual, psychosocial conflicts and in conflict with 'significant parental figure', often criticized by spouse as 'impotent', 'incapable' person challenging his 'maleness', got completely broken down with 'penile symptoms' (i.e symptoms of Koro), when 'rejected' (abandoned by father and spouse). This may possibly be because of overwhelmed 'castration anxiety' generated by the situation. And, the client believed (or in dilemma) that he was no more a 'male' (culturally and psychologically penis is a symbolic representation for male) and expressed this to the family and society in form of symptoms by saying that his penis was retracted into abdomen, to decrease the 'anxiety'. Perhaps, this may be an unhealthy compensatory mechanism to bring 'castration anxiety' level down. This is a possible hypothesis that needs to be tested in a long-term psychotherapy. Moreover, though the depressive symptoms improved moderately with medication, the Koro symptoms did not improved till psychosocial and psychotherapeutic interventions were made. The interventions were an attempt to give social stability, resolve the sexual and relationship conflicts, to a possible extent, with an intention to improve Koro symptoms. With improvement of 'Penile symptoms' depressive symptoms were resolved. In today's era of extinction of psychotherapeutic treatment, this case is a small example of how such comprehensive holistic treatments can be helpful not only in understanding but also in management of Koro syndrome, a culture bound syndrome, with depressive disorder, relevant to Indian context.

\section{REFERENCES}

1. Lewis-Sernandez R, Guarnaccia P, Ruiz P. Culture-bound Syndromes. In: Sadock BJ, Sadock VA. Kaplan and Sadock's Comprehensive Text Book of Psychiatry (9th ed). New York: Lippincort Williams and Wilkins Publishers 2010;2519-38.

2. The ICD-10 classification of mental and behavioral disorders clinical descriptions and diagnostic guidelines. World Health Organization, Geneva 2002;173.

3. Chakrobarty PK. Koro-a peculiar anxiety neurosis. Indian J Psychiatry 1982;24:192-93.

4. Ede A. Koro in an anglo-saxan Canadian. Canadian Psychiatric Association Journal 1976;21:389-91.

5. Nandi DN, Banerjee G, Saha H. Epidemic Koro in West Bengal, India. Int J Soc Psychiatry 1983;29:265-68.

6. Saji SD, Haque SN. Incomplete Koro-A forerunner for mood disorder: Two case reports. Indian J Psychiatry 1993;35:60-62.

7. Khubalkar R, Gupta OP. Psycho-dynamics of Koro. Indian J Psychiatry 1984;26:180-81.

8. Chowdhury AN. Trait anxiety profile of koro patients. Indian J Psychiatry 1990;32:330-33.

9. Shukla GD, Mishra DN. Koro like syndrome-a case report. Indian J Psychiatry 1981;96-97.

10. Avasthi AK, Varma VK, Nehra R, Das K. Construction and standardization of a sex knowledge and atitude (SKAQ) in simple Hindi for North Indian Population. Indian J Psychiatry 1994;34:24-27.

\section{ABOUT THE AUTHORS}

\section{Mahima Panigrahi}

Junior Resident, Department of Social and Preventive Medicine Jawaharlal Nehru Medical College, Wardha, Maharashtra, India

\section{Susanta Kumar Padhy (Corresponding Author)}

Assistant Professor, Department of Psychiatry, Postgraduate Institute of Medical Education and Research, Chandigarh, India e-mail: susanta.pgi30@yahoo.in

\section{Prakash B Behere}

Director (Research and Development), Professor and Head Department of Psychiatry, Jawaharlal Nehru Medical College Wardha, Maharashtra, India 